\title{
Unifocal Atrial Premature Complex by ECG
} Finding

National Cancer Institute

\section{Source}

National Cancer Institute. Unifocal Atrial Premature Complex by ECG Finding. NCI

Thesaurus. Code C102724.

An electrocardiographic finding of premature atrial complexes which have a single distinct morphology, suggesting origin at one atrial site. 